\title{
MIDAS
}

Museus e estudos interdisciplinares

$8 \mid 2017$

Dossier temático "Objetos e museus: biografias, narrativas e vínculos identitários"

\section{Objetos e museus: biografias, narrativas e vínculos identitários}

Objects and museums: biographies, narratives and identity bonds

\section{Alice Semedo, Olaia Fontal e Alex Ibanez}

\section{(2) OpenEdition}

\section{Journals}

Edição electrónica

URL: http://journals.openedition.org/midas/1169

DOI: $10.4000 /$ midas. 1169

ISSN: 2182-9543

Editora:

Alice Semedo, Paulo Simões Rodrigues, Pedro Casaleiro, Raquel Henriques da Silva, Ana Carvalho

Refêrencia eletrónica

Alice Semedo, Olaia Fontal e Alex Ibanez, « Objetos e museus: biografias, narrativas e vínculos identitários », MIDAS [Online], 8 | 2017, posto online no dia 31 julho 2017, consultado no dia 19 abri 2019. URL : http://journals.openedition.org/midas/1169; DOI : 10.4000/midas.1169

Este documento foi criado de forma automática no dia 19 Abril 2019.

\section{cc) (†)}

Midas is licensed under a Creative Commons Attribution-NonCommercial-ShareAlike 3.0 International License 


\section{Objetos e museus: biografias, narrativas e vínculos identitários}

Objects and museums: biographies, narratives and identity bonds

Alice Semedo, Olaia Fontal e Alex Ibanez

\section{Dos museus contentores aos museus como espaços de património}

1 Desde meados da década de 1980, os museus e o património têm sido objeto de atenção académica e política em muitos países ocidentais, assistindo-se a transformações na perceção do seu papel e a uma mudança de paradigma (pelo menos em termos retóricos), do "museu como um templo" para "um museu como fórum", do museu mero armazémcontentor ao museu agente cultural (Levi 1985), referente comunitário e agitador de pensamento (Poussou 2007), agente de inclusão e de encontro para conhecer e até mesmo curar (Torregrosa 2017) e, como resultado, a um entendimento dos museus como espaços para a diversidade e democracia. Na realidade, os museus contêm o património do presente - mesmo quando contêm parte da história, esta é uma referência identitária de hoje -, dirigindo-se, oportunamente, aos seus legatários mais próximos, habitantes da mesma época e contextos. Neste sentido, os museus são concebidos e atuam como agentes patrimonializadores, procurando a apropriação simbólica e a caracterização de contextos culturais: do presente social, político, económico...; a definição de um referente identitário próprio, com valores particulares do presente. Referindo-se, em última análise, a museus que ativam a continuidade do fio da memória (Olmos 2004).

\section{Das pessoas aos objetos concebidos como registos de identidades e portadores de vínculos}

2 Os objetos estão de volta à teoria social contemporânea com uma nova força. Seja na forma de bens de consumo, tecnologias de comunicação, obras de arte ou mesmo de 
espaços urbanos, um novo mundo de materialidades e objetividades surge agora com uma urgência que os transformou em novos lugares de questionamento e de reflexão. Se as visões pós-estruturalistas e construtivistas de caráter mais radical tenderam a liquefazer tudo o que era sólido, agora é precisamente a solidez do que nos rodeia que nos capta a atenção, levando-nos, por exemplo, a atentar no imediatismo sensorial dos objetos com que vivemos, trabalhamos e conversamos, amamos e odiamos. A materialidade volta a ocupar um lugar central no discurso e na prática museológica e patrimonial, reimaginando, a cada passo, o que de facto constitui esta materialidade.

Diferentes abordagens no âmbito da Museologia, antropologia, geografia, cultura material, estudos de ciência e tecnologia, design, sociologia do consumo e da cultura para nomear apenas algumas -, apontam para uma compreensão da capacidade performativa e integradora dos objetos para ajudar a construir aquilo a que chamamos sociedade. Novas abordagens em relação à cultura material e visual, ao estudo de artefactos e das histórias enredadas de coleções apresentam o museu como um laboratório e a coleção como uma tecnologia de pesquisa. Importantes projetos interdisciplinares utilizam as coleções como forma de aproximação a questões mais amplas relacionadas com a arte, a cultura, a história ou mesmo com o meio ambiente. Métodos que nos chegam dos estudos literários, por exemplo, desenham abordagens para analisar objetos de memória bem reveladoras do apetite por novas formas de problematização e enquadramento destes temas. Este enfoque, de caráter mais literário, encontra-se bem patente em muitos trabalhos recentemente publicados, incluindo, Uma História do Mundo em 100 Objetos (MacGregor 2014), A Lebre dos Olhos de Âmbar (De Waal 2012), Objetos Evocativos: Coisas Com Que Pensamos (Turkle 2007), 'Parafernalia': La Curiosa Historia de Nuestros Objetos Cotidianos (Connor 2011), O Bacalhau - Biografia do Peixe que Mudou o Mundo (Kurlansky 2000) ou Biografias de Objetos Científicos (Daston 2000). A abordagem biográfica de objetos levanta questões metodológicas substanciais relacionadas com a sua narrativa, estrutura e cronologia, representação da mudança, influência nas vidas humanas, comunidades e história material e, crucialmente, com a sua interpretação e visibilidade em museus. O estudo de caráter biográfico de objetos tem proporcionado áreas de pesquisa académica extremamente produtivas e inovadoras, incluindo o trabalho de Bill Brown sobre Thing Theory (2001); de Chris Gosden, Frances Larson e Alison Petch (2007) a partir das coleç̃oes do Museu Pitt Rivers; e, claro, os ensaios incluídos no volume já clássico editado por Arjun Appadurai, em 1986, nomeadamente sobre o valor e a troca de objetos.

4 Ao concentrar-se mais atentamente na vida social dos objetos e nos seus efeitos expressivos, retroativos ou interpelantes da atividade humana, este número da MIDAS pretende incluir visões transversais entre os vários "novos materialismos", forjando, ao mesmo tempo, ligações críticas com tropos mais clássicos e temas da história da Museologia. Para além disso, ao incorporarmos os aspetos intangíveis (históricos, emocionais, espirituais) e relacionais (propriedade, pertença e identidade) dos objetos em museus, abrem-se, ainda, outras possibilidades de exploração que permitem a problematização de abordagens de educação que representam o museu como contentor de património. Assim, considera-se o património como a relação que ocorre entre bens e pessoas, relação capaz de conectar os bens culturais com a sociedade a que pertence e o tempo legatário. Nessa lógica, os objetos convertem-se numa espécie de portadores de identidade que assume corporeidade através de narrativas, biografias e construções artísticas que se apresentam como uma manifestação do vínculo gerado entre os bens 
culturais e as pessoas. De resto, a criação de tais ligações não acontece apenas no espaço físico dos museus, mas, e cada vez mais, noutros espaços (incluindo virtuais). Todas estas relações são diferentes formas de manifestação da mesma aproximação: a relação de identidade entre indivíduos ou grupos e elementos patrimoniais.

O artigo de Carmen Gómez-Redondo, «El Objeto Patrimonial como Símbolo Identitario en el Museo», com o qual iniciamos este dossier, introduz algumas destas questões, relacionando-as com uma reflexão sobre os modos através dos quais os indivíduos se relacionam com os objetos e a sua mediação. A autora explica que quando nos referimos a objeto não nos referimos somente a uma "coisa", mas sim a um sistema simbólico que representa a cultura em que se inscreve e os seus processos metaculturais. Será neste sistema de simbolização que introduz o termo património, compreendido como parte desses processos metaculturais e, nesse aspeto, definindo-o enquanto vínculo significativo que os indivíduos atribuem a diferentes manifestações culturais e, neste caso, aos objetos. Esta reconceptualização a partir da relação objeto/sujeito, gera novas formulações em torno dos processos de produção de património/museu apontando para um modelo de museu enculturador que não só se aproxima de interpretações plásticas dos objetos, mas também da diversidade de perspetivas, incluindo a identitária.

Neste dossier encontramos um importante grupo de artigos que se articulam em torno de relatos individuais: narrativas, biografias, construções artísticas em redor do objeto musealizado. Neste grupo incluem-se artigos que oferecem relatos biográficos de objetos particulares tal como o de Patricia Delayti Telles, que seleciona um grupo de miniaturas de "filiação política" para nos apresentar uma reflexão sobre o quase-esquecimento de objetos, cujo poder simbólico e vivência se encontram "silenciados" pela sua inclusão em contextos museológicos. Centrando-se no cofre-relicário de Francisco Xavier do Museu de São Roque, da Santa Casa da Misericórdia de Lisboa, Inês Lourenço explora a potencialidade dos objetos e dos museus para gerar narrativas alternativas, analisando o modo como as pessoas usam objetos para as contar. A autora propõe-nos uma reflexão sobre os processos identitários dos goeses em Portugal, analisando, especificamente, formas de relacionamento entre as pessoas e os objetos materiais, situando os objetos religiosos como exemplo de extraordinário potencial simbólico e de produção de narrativas alternativas. De maneira importante, a autora argumenta que estes objetos podem ser utilizados como veículos para pensar não só o passado (das trajetórias migratórias), mas também as dinâmicas complexas das sociedades contemporâneas, e desta forma, desafiar as narrativas dominantes. No texto de Márcia Pinheiro Ferreira e Marcos Granato, a Luneta de Bamberg do acervo do Museu de Astronomia e Ciências Afins (MAST), no Rio de Janeiro, é protagonista de uma pesquisa de trajetória baseada no conhecimento transversal da biografia da conservação e da cultura das coisas e na própria metodologia de investigação de objetos. Os ciclos de vida dos objetos são também evocados no projeto que Ribeiro et al. nos trazem. A partir de uma análise assente nas dualidades que, eventualmente, determinam as ideias de vida/morte, o corpo/alma/ materialidade e imaterialidade de três objetos - um vestido (museu); uma pintura de altar (igreja) e uma fonte (espaço público) - os autores ensaiam uma reflexão sobre a deterioração, o desaparecimento e a destruição destes três artefactos.

7 A documentação, os testemunhos dos protagonistas e a observação servem de lente para explorar as biografias de diferentes objetos, quer se trate de uma coleção etnográfica, quer do museu-artefacto ou mesmo de uma instalação de arte contemporânea, permitindo a análise de diferentes configurações e a materialização da memória dos 
vínculos identitários que os objetos retêm. Em «Por detrás de uma coleção do Museu Nacional (Rio de Janeiro, Brasil): vozes, silêncios e desafios», Cecilia de Oliveira Ewbank e Manuel Ferreira Lima Filho destrinçam os sedimentos de diferentes camadas de documentação para nos revelar o silenciamento de algumas características biográficas dos artefatos das coleções dos museus etnográficos, especialmente no que diz respeito ao contexto da sua aquisição. A análise da trajetória das salas - pensadas enquanto objetos de museu (museália) - do Museu Casa Rui Barbosa, na cidade do Rio de Janeiro (Brasil) levada a cabo por Aparecida Marina de Souza Rangel e Álea Santos de Almeida, torna-se de primeira importância para o desenvolvimento de uma metodologia de pesquisa que repensa a documentação e o inventário desses espaços enquanto artefactos. Também a biografia da obra Oh la la,... oh la balançoire/ Microcosmos Tentacular, de Susanne Themlitz, que Cristina Barros de Oliveira nos propõe, se constrói no cruzamento de informações documentais com aquelas obtidas junto dos diversos intervenientes na vida desta instalação, não só através de entrevistas, mas da observação do processo de montagem da obra e das discussões que estiveram na base de certas decisões. A autora parte da análise desta exposição para pensar algumas das premissas que se alteram ao longo do tempo, em cada nova apresentação da instalação. A noção de qualidade estática da obra de arte é questionada obrigando o museu a compreender este objeto a partir do entendimento do percurso da obra e das relações que foi traçando, não só com diferentes espaços, mas também com distintos momentos da carreira do artista ou até com outros intervenientes na "vida" da obra. Entendimento que é consequente quer na forma como o museu desenvolve estratégias de conservação, quer nos modos de comunicar a obra ao público.

O artigo de Margarida Alves centra-se na produção objetual de Salette Tavares, em particular nos designados Diálogos Criativos, um conjunto de objetos, desenvolvido entre 1959 e 1971. Tal como a sua poesia, também estas peças são permeadas por uma dimensão quotidiana - não apenas porque se tratam de objetos que, na sua maioria, incorporam uma valência funcional, mas também porque, em alguns casos, funcionam como um suporte para o registo da sua própria vida pessoal, apagando, assim, os supostos limites entre o artístico e o não-artístico e constituindo-se como objetos para explorar possibilidades de construções de auto/biografia. Ao mesmo tempo, estes são objetos que incorporam elementos que implicam outros tempos, outros lugares, outras histórias. Nesses poemas surrealizantes, em que iminentemente tudo pode acontecer, não distinguimos quaisquer fronteiras entre o vivo e o inanimado, entre a realidade e o sonho, entre o possível e o impossível, ou até entre o pessoal e o universal. Nesse sentido, Margarida Alves analisa as tensões que esses objetos estabelecem entre físico e imaterial, entre pessoal e relacional, ou mesmo entre arte e vida, problematizando, ainda, a alteração operada nesses objetos através da sua deslocação de uma esfera quotidiana, para um sistema expositivo.

9 Um outro enfoque que encerra o dossier, refere-se à relação objeto-aprendizagem privilegiada em museus. É comum afirmar-se que os objetos facilitam a aprendizagem através do desenvolvimento de competências de observação e de questionamento, permitindo conotações emocionais e fazendo com que ideias complexas se tornem compreensíveis. Neste ponto, privilegiou-se a apresentação de discussões sobre estes conceitos a partir de investigação baseada, por exemplo, em estudo de casos. Estes artigos dão a conhecer o "valor acrescentado" que a aprendizagem baseada em objetos nos traz. Apresentam abordagens utilizadas em museus ou referem-se explicitamente à educação 
dos educadores e a exemplos que exploram a aprendizagem baseada em objetos e às relações estabelecidas com a criatividade.

O trabalho desenvolvido por Sofía Marín Cepeda com estudantes do Grado de Magisterio de Educación Primaria na Universidade de Valladolid, serve de mote para a discussão que nos expõe sobre a importância dos objetos como chave de aprendizagem em espaços informais e da sua importância na formação de educadores. A autora apresenta a proposta educativa «Patrimonio en conserva» assente na noção de vínculos identitários compreendidos como chave de conscientização e produção de aprendizagens transmissíveis, em torno do objeto artístico e da valorização do património. Trata-se de um exemplo de trabalho em contexto de sala de aula que, partindo de vínculos entre os alunos e do seu património mais pessoal, gera artefactos e relatos que permitem viabilizar relações e, deste modo, possibilitar a transferência de aprendizagens para contextos mais amplos. No artigo «Patrimonios, Objetos e Historias de Vida. Análisis de Propuestas Educativas desde el OEPE», de Olaia Fontal, Silvia García, Borja Aso e Marta Martínez, encontramos a trajetória de uma série de ações e programas educacionais sobre bens pessoais, objetos, património imaterial, laços e afetos desenvolvidos no triângulo de pesquisa definido nos contextos formativos e culturais de Espanha, Portugal e Brasil. Neste artigo, os autores analisam programas que enfatizam o compromisso social do património, projetos artísticos que partem do património nos seus processos criativos vinculando histórias de vida e, por fim, ações colaborativas em rede, que se focam no património enquanto espaço de relações, emoções, memórias e laços entre pessoas e bens.

Este número da revista MIDAS faz parte do esforço atual para reunir diferentes perspetivas (museológica, curatorial, teórica) sobre o lugar dos objetos em museus, a fim de mapear criticamente este domínio. Em suma, trata-se de refletir e apresentar exemplos relevantes que permitam recuperar a teorização sobre objetos em museus como portadores não apenas de significados sociais, mas também individuais, permitindo que os processos de patrimonialização e identização sejam também explorados a partir do ponto de vista da educação. Os tópicos/questões propostas sobrepõem-se parcialmente permitindo o confronto de vários pontos de vista teóricos e metodológicos e a produção de materiais diversificados.

12 Finalizamos agradecendo o interesse e o contributo de todos aqueles que enviaram as suas propostas de artigos, a disponibilidade de todos os referees, o esforço atento de Inmaculada Sánchez Macías, Jesús Marín Cepeda e Silvia García Ceballos, o trabalho generoso de Álvaro Pérez Mulas e de Elisa Noronha, e o apoio de sempre de Ana Carvalho, que mais uma vez tornaram possível um número da MIDAS.

\section{BIBLIOGRAFIA}

Appadurai, Arjun, ed. 1986. The Social Life of Things: Commodities in Cultural Perspetive. Cambridge: Cambridge University Press.

Brown, Bill. 2001. “Thing Theory.” Critical Inquiry 28, 1, Things (Autumn): 1-22. 
Connor, Steven. 2011. 'Parafernalia': La Curiosa Historia de Nuestros Objetos Cotidianos/Paraphernalia: The Curious Life of Magical Things. Barcelona: Editorial Ariel.

Daston, Lorraine, ed. 2000. Biographies of Scientific Objects. Chicago: University of Chicago Press.

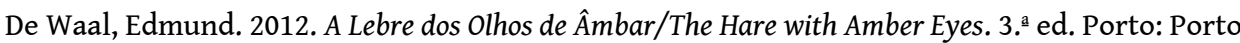
Editora/Sextante.

Gosden, Cris; Frances Larson, e Alison Petch. 2007. Knowing Things: Exploring the Collections at the Pitt Rivers Museum, 1884-1945. Oxford: Oxford University Press.

Kurlansky, Mark. 2000. O Bacalhau - Biografia do Peixe que Mudou o Mundo/Cod - A Biography of the Fish That Changed the World. Lisboa: Terramar.

Levi, Albert William. 1985. "The Art Museum as an Agency of Culture." The Journal of Aesthetic Education 19, II, 23-40.

MacGregor, Neil. 2014. Uma História do Mundo em 100 objetos/A History of the World in 100 Objects. Lisboa: Temas e Debates e Círculo de Leitores.

Olmos, Ricardo. 2004. "Reflexiones al Hilo de una Pasada Experiencia en Museos." Museos.es: Revista de la Subdirección General de Museos Estatales, 0, 14-25.

Poussou, Vincent. 2007. "Entre Utopía y Realidad: Aciones Innovadoras y Estrategias de Públicos.” In Espacios Estimulantes. Museos y Educación Artística, editado por Ricard Huerta Ramón, e Román de la Calle, 167-177. València: Universitat de València.

Torregrosa, Apolline. 2017. “Résonances Artistiques pour la Santé." Ethics, Medicine and Public Health 3, 135-140.

Turkle, Sherry, ed. 2007. Evocative Objects: Things We Think With. Cambridge: MIT Press.

\section{AUTORES}

\section{ALICE SEMEDO}

Professora auxiliar do Departamento de Ciências e Técnicas do Património e investigadora integrada do CITCEM - Centro de Investigação Transdisciplinar Cultura, Espaço e Memória da Universidade do Porto (Portugal). Tendo atuado como diretora do mestrado (entre 2003-2013) e do doutoramento em Museologia (a partir de 2013), participou em diferentes projetos de investigação e orientou cerca de três dezenas de dissertações de mestrado e cinco teses de doutoramento (duas delas já publicadas) sobre tópicos como: as narrativas e os discursos museológicos, as identidades profissionais em museus, a criatividade nos museus e os espaçosentre da mediação, ou as missões de museus no mundo contemporâneo. asemedo@letras.up.pt

\section{OLAIA FONTAL}

Licenciada em Belas Artes pela Universidade do País Basco/Euskal Herriko Unibertsitatea e licenciatura em História da Arte e doutorada em Ciências da Educação pela Universidade de Oviedo (Espanha). É professora titular na Universidade de Valladolid em Educação Artística e autora de numerosos livros e artigos indexados sobre o tema da educação patrimonial. Dirige atualmente o Observatório de Educação Patrimonial em Espanha (OEPE), tendo participado numa sucessão de três I+D+i e é co-coordenadora do Plano Nacional de Educação Patrimonial de Espanha. olaia.fontal@uva.es 


\section{ALEX IBANEZ}

Licenciado em Geografia e História e doutorado em Ciências da Educação, é professor titular de Ensino de Ciências Sociais na Universidade do País Basco. Especialista em Educação Patrimonial e docente de investigação em Didáticas do Património na Universidade de Huelva (Espanha), tendo coorientado quatro teses de doutoramento, neste âmbito. Desde 2006 tem participado continuamente em equipas de I+D+i do MINECO, sendo atualmente investigador principal num destes projetos. É membro da rede de excelência em investigação de Ciências Sociais - Red14 e foi autor do Plano Nacional de Educação Patrimonial de Espanha. alex.ibanez@ehu.es 